\title{
Assessment of Different Culture Media on the Growth and Sporulation of Alternaria cucumerina var. cyamopsidis causing Alternaria blight of Clusterbean
}

\author{
Satish Sharma*, Pragati Saini, Ajay Kumar, Reeti Singh and R.K. Pandya \\ Department of Plant Pathology, College of Agriculture, R.V.S.K.V.V. Gwalior (MP), India \\ *Corresponding author
}

\begin{tabular}{|c|c|}
\hline & B S T R A C T \\
\hline Keywor & \multirow{4}{*}{$\begin{array}{l}\text { Alternaria blight is the most common and devastating disease caused by Alternaria } \\
\text { cucumerina var. cyamopsidis in Clusterbean. This fungus grows well in Potato dextrose } \\
\text { agar and Tomato dextrose agar medium under in vitro conditions. The growth of the } \\
\text { fungus was tested using fifteen different media. PDA appeared to be better than other } \\
\text { media for the growth of Alternaria cucumerina var. cyamopsidis. The growth } \\
\text { characteristics of the fungus such as colour of the colony and sporulation were also } \\
\text { different in different culture media. The colony of the fungus was dark brown in colour. } \\
\text { Maximum sporulation of the test fungus was found on PDA medium whereas no } \\
\text { sporulation was seen on Czapeck's dox agar medium. Thus the present work will be useful } \\
\text { for further investigation on the physiology of the fungus and management of the disease. }\end{array}$} \\
\hline & \\
\hline Art & \\
\hline $\begin{array}{l}\text { Accepted: } \\
\text { 24 August } 2018 \\
\text { Available Online: } \\
\text { 10 September } 2018\end{array}$ & \\
\hline
\end{tabular}

\section{Introduction}

Clusterbean commonly recognized as a summer, annual, drought-tolerant and well adapted to arid and semi-arid climates with hot temperatures legume crop. It can grow in sub humid conditions, from sea level upto an altitudes of 1000 m (Priya and Harika, 2016).

It is an important Kharif crop grow widely for grain, green fodder, vegetable, green manuring and for seed purposes. Clusterbean has become popular not only for consumption as vegetable but also as good source of useful industrial "Guar gum" (Reddy et al., 2017). The seeds are nutritionally rich in energy (16K cal), moisture $(81 \mathrm{~g})$, protein $(3.2 \mathrm{~g})$, fat (1.4 g), carbohydrate (10.8 g), vitamin A (65.3 IU), vitamin C (49 mg), calcium $(57 \mathrm{mg})$ and iron $(4.5 \mathrm{mg})$ for every $100 \mathrm{~g}$ of edible portion (Kumar and Singh, 2002).

The production and productivity of Clusterbean in terms of grain and fodder is highly affected by a number of phytopathogenic fungal diseases. Alternaria spp. are economically important pathogens widely distributed throughout the world and cause devastating disease on field crops. Alternaria leaf blight is a common disease in guar-growing area of western India. The disease appears year after year in mild to severe form since the pathogen is seed- borne in nature. In early stages of infection, the 
water soaked spots appear on leaf blade which later turn greyish to dark brown with concentric zonation, demarcated with light brown lines inside the spot on the under surface. The lesions are light to greyish brown. Higher yield losses (43-78 \%) were recorded when leaves were infected at seedling stage than at old stage (Sharma, 1984).

The present study is focused on the growth and colony characteristics of Alternaria cucumerina var. cyamopsidis using different growth medium for the knowledge of nutritional pattern and factors influencing the growth of the this pathogen.

\section{Materials and Methods}

Different common synthetic, semi synthetic and natural media in solid form were used to culture the fungus. The purified culture of the fungus was inoculated into 15 different culture media viz., Pea husk dextrose agar (PHDA), Cabbage dextrose agar (CDA), Pea grain dextrose agar (PGDA), Carrot potato dextrose agar (CPDA), Marry gold leaf dextrose Agar (MGLDA), Malt apple dextrose agar (MADA), Cluster bean leaf dextrose agar (CBDA), Reddish potato dextrose agar (RPDA), Malt dextrose agar (MDA), Tomato dextrose agar (TDA), Potato leaf dextrose agar (PLDA), Water agar (WA), Czapeck's dox agar (CDA), Cauliflower dextrose agar (CDA), Potato dextrose agar (PDA).

These media contain various elements in 1000 $\mathrm{ml}$ of distilled water viz., PHDA (Pea husk extract $200 \mathrm{ml}$, dextrose $20 \mathrm{~g}$, agar-agar $20 \mathrm{~g}$ ), CD (cabbage leaf $200 \mathrm{~g}$, dextrose $20 \mathrm{~g}$, agaragar $20 \mathrm{~g}$ ), PGDA (Pea grain $200 \mathrm{ml}$, dextrose $20 \mathrm{~g}$, agar-agar $20 \mathrm{~g}$ ), CPDA (Grated potato $200 \mathrm{~g}$, grated carrot $20 \mathrm{~g}$, agar-agar $20 \mathrm{~g}$ ), MGLD (Marigold leaf $200 \mathrm{~g}$, dextrose $20 \mathrm{~g}$, agar-agar 20g), MADA (apple juice $50 \mathrm{ml}$, malt extract $20 \mathrm{~g}$, agar-agar $20 \mathrm{~g}$ ), CBDA (cluster bean leaf $200 \mathrm{~g}$, dextrose $20 \mathrm{~g}$, agaragar 20 g), RPDA (radish 200 g, dextrose 20 g, agar-agar $20 \mathrm{~g}$ ), MDA (Malt extract $20 \mathrm{~g}$, peptone $10 \mathrm{~g}$, dextrose $20 \mathrm{~g}$, agar-agar $20 \mathrm{~g}$ ), TD (Tomato $200 \mathrm{~g}$, dextrose $20 \mathrm{~g}$, agar-agar $20 \mathrm{~g}$ ), PLDA (Potato leaf $200 \mathrm{~g}$, dextrose $20 \mathrm{~g}$, agar-agar $20 \mathrm{~g}$ ), WA (Distilled water $1000 \mathrm{ml}$, agar-agar-20 g), CDA (sucrose $30 \mathrm{~g}$, sodium nitrate $2 \mathrm{~g}$, di potassium hydrogen phosphate 4 $\mathrm{g}$, magnesium sulphate $0.001 \mathrm{~g}$, agar-agar 20 g), CDA (Cauliflower leaf $200 \mathrm{~g}$, dextrose 20 g, agar-agar $20 \mathrm{~g}$ ), Potato dextrose agar (PDA).

Water agar medium is used to compare the growth of A. cucumerina var. cyamopsidis. The culture media were prepared by the standardized method and autoclaved at $121{ }^{\circ} \mathrm{C}$ at 15 psi pressure for 20 minutes.

After autoclaving penicillin $(200 \mathrm{mg} / \mathrm{l})$ was added to prevent the bacteria growth. Uniform quantities $(20 \mathrm{ml})$ of each medium were poured into $90 \mathrm{~mm}$ Petri plate. Each Petri plate was inoculated separately with uniform mycelia culture bits $(5 \mathrm{~mm})$ cut with the help of cork borer from young fresh growing culture, were placed on the centre of each Petri plate and incubated at $25 \pm 2{ }^{0} \mathrm{C}$. The experiment was performed in triplicate form.

The fungal linear growth was measured in mm after 7 days of inoculation (Koley and Mahapatra, 2015). The colour of the colony was observed by naked eye. For measuring the sporulation on different media, a single block of $\mathrm{mm}$ diameter was cut out from the fungal colony near the margin by sterilized cork borer and was transferred to $5 \mathrm{ml}$ sterile distilled water in a test tube, where it was mixed thoroughly to make a uniform spore suspension. One small drop of spore suspension was taken on a slide and average spore count of three microscopic fields was recorded under low power $(10 \mathrm{x})$ objective of the microscope. 


\section{Results and Discussion}

\section{Radial growth of the pathogen}

The culture of the plant pathogen on or in the suitable medium is the first step of pathological research. In present research work the table 1 showed that fifteen culture media were evaluated to find out the most effective medium for the growth of $A$. cucumerina var. cyamopsidis in in vitro conditions (Figure 1).

The data reveals that Potato dextrose agar medium $(84.16 \mathrm{~mm})$ was significantly superior over other tested media after 7 days of inoculation. It was followed by Tomato leaf dextrose agar $(78.84 \mathrm{~mm})$, Cluster bean leaf dextrose agar $(70.89 \mathrm{~mm})$, Potato leaf dextrose agar $(68.33 \mathrm{~mm})$, Malt dextrose agar $(58.83$ $\mathrm{mm}$ ), Marigold leaf dextrose agar (50.16), Pea grain dextrose agar medium $(48.33 \mathrm{~mm})$, Cauliflower leaf potato dextrose agar (48.12 $\mathrm{mm})$, Cabbage dextrose agar (43.66 $\mathrm{mm}$ ), Malt apple dextrose agar $(43.33 \mathrm{~mm})$, Reddish potato dextrose agar $(40.00 \mathrm{~mm})$, Pea husk dextrose agar $(36.83 \mathrm{~mm})$ and water agar $(32.36 \mathrm{~mm})$. No growth was observed in Czapeck's dextrose agar medium (Plate-1).

\section{Colour of the culture}

Variation in the colour of colony and topography of mycelium showed the important information which may helpful in taxonomic identification of $A . \quad c$. var. cyamopsidis. Among all media tested for evaluation, the colour of culture was slightly different from each other. The substrate colour of the colony was dark brown on Marry gold leaf dextrose agar, Malt apple dextrose agar, Cauliflower leaf potato dextrose agar and Potato dextrose agar whereas light brown colour was shown by Pea husk dextrose agar, Malt dextrose agar, Czapeck's dextrose agar and Tomato leaf dextrose agar. The black colour of the colony was found in the Cluster bean leaf dextrose agar, Reddish potato dextrose agar and Water agar. The cabbage dextrose agar revealed the light green colour of the colony.

Excellent sporulation (more than 30 spores / microscopic field) of the fungus was observed on Potato dextrose agar and Tomato dextrose agar medium whereas good sporulation (21-30 spores / microscopic field) was observed on Marry gold leaf dextrose agar, Cluster bean dextrose agar, Malt dextrose agar and Potato leaf dextrose agar. Moderate sporulation (1120 spores / microscopic field) was observed on Cabbage dextrose agar, Pea grain dextrose agar, Malt apple dextrose agar, Reddish potato dextrose agar and Cauliflower dextrose agar but poor sporulation (1-10 spores / microscopic field) was observed on Pea husk dextrose agar, Carrot potato dextrose agar and Water agar. Sporulation of the fungus could not be observed in case of Czapeck's dextrose agar medium.

Meena and Ratnoo (2013) observed that the excellent growth and sporulation was found on potato dextrose agar which was followed by malt extract agar medium in vitro conditions. Many workers have found PDA as best and Brown's medium and Asthana and Hawker's media very poor for Alternaria spp. for growth and sporulation in laboratory studies (Singh $e t$ al., 2001; Pandey et al., 2006; Waghunde and Patil, 2010).

Total fifteen culture media were evaluated for the growth of $A$. $c$. var. cyamopsidis under in vitro conditions in which maximum mycelial growth was found in potato dextrose agar media followed by Tomato leaf dextrose agar media while least growth was observed in water agar medium. The present finding is conformity with the reports of earlier study by Pria et al., (1997), Mishra and Mishra (2012) and Munde et al., (2013). 
Table.1 Efficacy of different media on the growth of Alternaria cucumerina var. cyamopsidis

\begin{tabular}{|c|c|c|c|c|c|}
\hline S.N. & Culture medium & $\begin{array}{c}\text { Mycelial } \\
\text { growth (mm) }\end{array}$ & Colour of colony & Sporulation & $\begin{array}{c}\text { No. of } \\
\text { spores/microsc } \\
\text { opic field }\end{array}$ \\
\hline 1 & Pea husk dextrose agar & $36.83(37.26)$ & Light brown colour & + & $1-10$ \\
\hline 2 & Cabbage dextrose agar & $43.66(41.33)$ & Light green & ++ & $11-20$ \\
\hline 3 & Pea grain dextrose agar & $48.33(44.02)$ & Dark black colour & ++ & $11-20$ \\
\hline 4 & Carrot potato dextrose agar & $39.53(38.94)$ & Light brown & + & $1-10$ \\
\hline 5 & Marry gold leaf dextrose agar & $50.16(45.07)$ & Dark brown & +++ & $21-30$ \\
\hline 6 & Malt apple dextrose agar & $43.33(41.14)$ & Dark brown & ++ & $11-20$ \\
\hline 7 & Cluster bean leaf dextrose agar & $70.89(57.33)$ & Black & +++ & $21-30$ \\
\hline 8 & Reddish potato dextrose agar & $40.00(39.21)$ & Black & ++ & $11-20$ \\
\hline 9 & Malt dextrose agar & $58.83(50.06)$ & Light brown & +++ & $21-30$ \\
\hline 10 & Tomato dextrose agar & $78.84(62.59)$ & Light brown & ++++ & $31-40$ \\
\hline 11 & Potato leaf dextrose agar & $68.33(55.73)$ & Light black & +++ & $21-30$ \\
\hline 12 & Water agar & $32.36(34.45)$ & Black & + & $1-10$ \\
\hline 13 & Czapeck's dextrose agar & $0.0(0.0)$ & Light brown & - & 0 \\
\hline 14 & Cauliflower dextrose agar & $48.12(43.90)$ & Dark Brown & ++ & $11-20$ \\
\hline 15 & Potato dextrose agar & $84.16(66.52)$ & Dark Brown & ++++ & $31-40$ \\
\hline & C.D. at $5 \%$ & 2.08 & - & & \\
\hline & $\mathrm{SE}(\mathrm{m})$ & 0.71 & - & & \\
\hline
\end{tabular}

- (Nil), + (Poor), ++ (Moderate), +++ (Good), ++++ (Excellent)

The values in parenthesis are angular transform value.

Fig.1 Efficacy of different culture media for the growth of A. cucumerina var. cyamopsidis after 7 days of inoculation

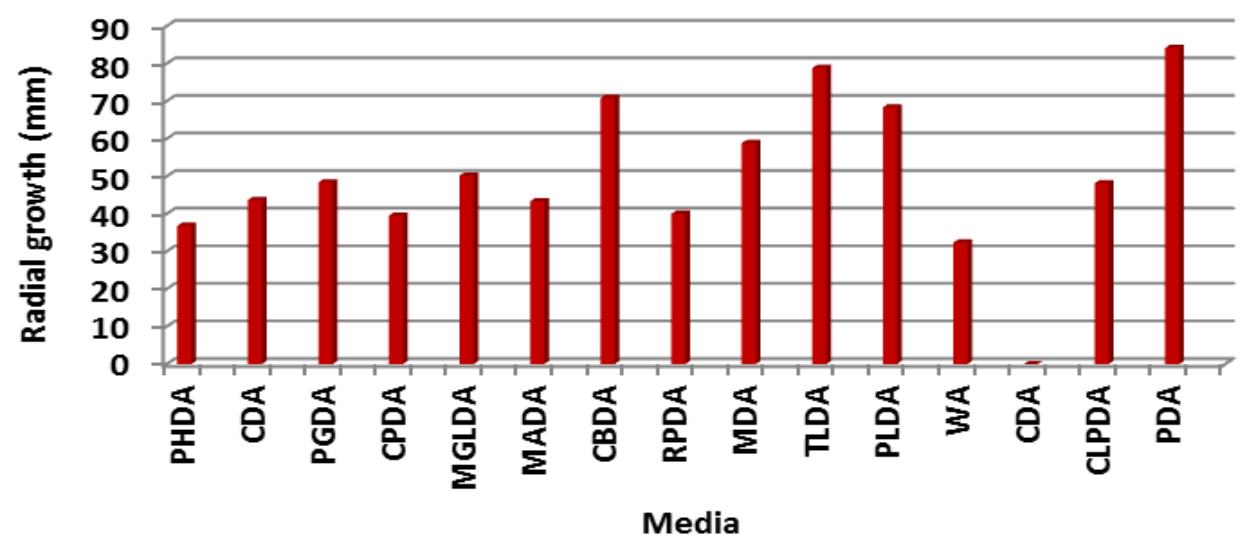


Plate.1 Evaluation of different media for the growth of Alternaria cucumerina var. cyamopsidis

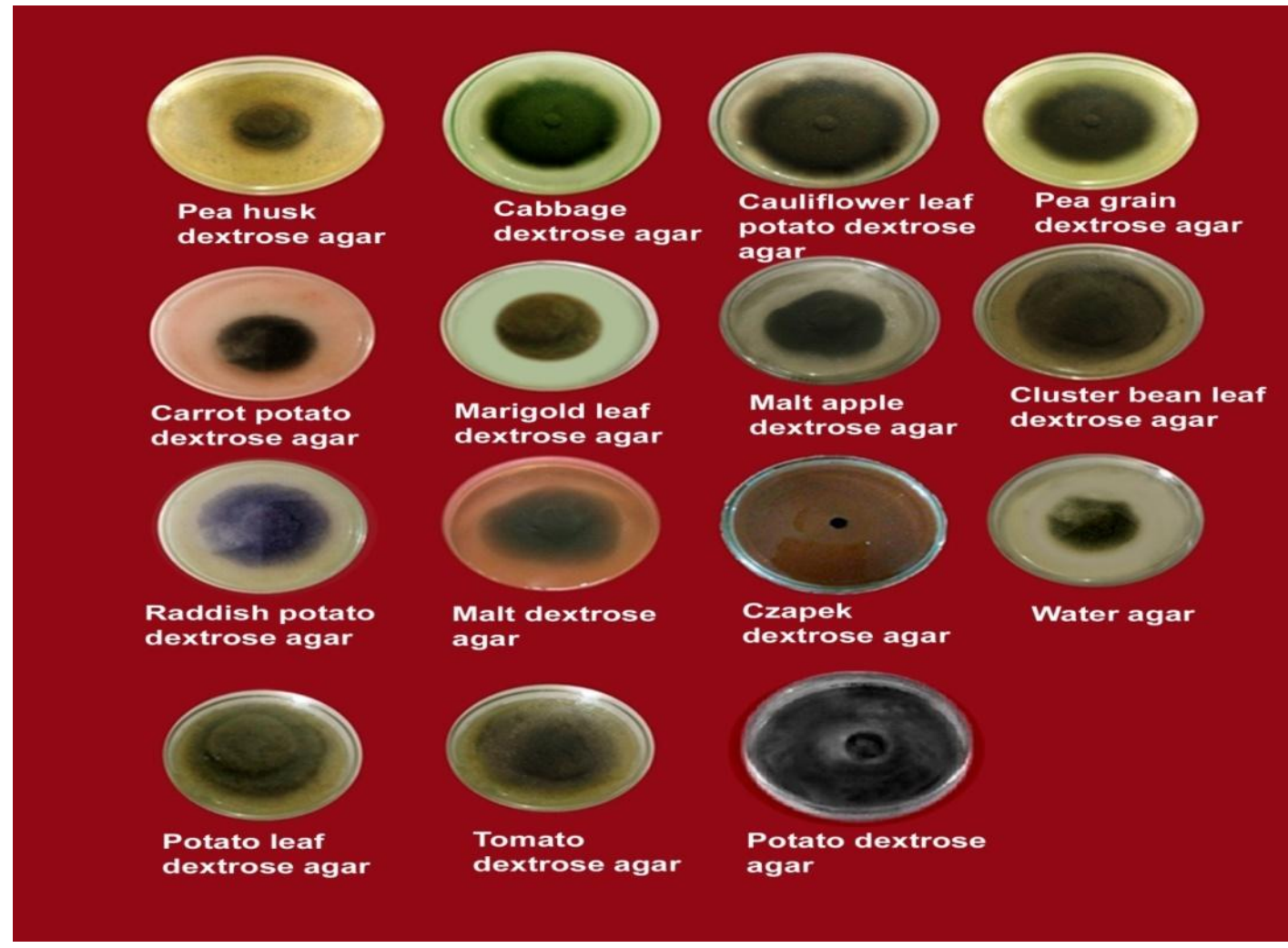

They reported that the fungus was found to grow on all the culture media tested, but semisynthetic solid media PDA was more favourable for fungus growth. It is concluded that PDA has the simple formulation and more nutrient contents, which support the mycelial growth of the fungus (Saha et al., 2008). The present findings were also parallel with Singh et al., (2013) who reported that Alternaria species showed the highest radial growth on PDA medium out of nine tested solid media and poor sporulation was noticed on host extract agar medium.

This investigation reveals that Potato dextrose agar medium influences the best radial growth of A. c. var. cyamopsidis. The study will be helpful to understand the growth and its management to combat the disease. Moreover, use of different culture media will be helpful to determine the growth parameter of the test fungus.

\section{Acknowledgement}

The authors are grateful to Dean, College of Agriculture, Gwalior, for providing the lab and field facility for the research work.

\section{References}

Koley, S., and Mahapatra, S. 2015. Evaluation of culture media for growth characteristics of Alternaria solani causing early blight of Tomato. J. Plant Pathol Microbiol. 9(1): 1-5.

Kumar, D., and Singh, N.B. 2002. Guar in India, Scientific publishers (India), Jodhpur.

Meena, P. K., and Ratnoo, R.S. 2013. Effect of growth and sporulation on different solid media and toxin production by Alternaria spp. causing leaf spot on cotton. International J. Plant Protect. 6(1):293-295. 
Mishra, P.T., and Mishra, V. 2012. Effect of media, temperature, and $\mathrm{pH}$ on the growth of Alternaria alternata causing leaf spot of cotton. Annals Plant Protect. Sci. 20: 246-247.

Munde, V.G., Diwakar, M.P., Thombre, B.B., and Dey, U. 2013 Cultural and morphological characters of Alternaria solani on different media. Bioinfolet. 10: 984-986.

Pandey, B.N., Srivastava, S.P., and Srivastava, R.K. 2006. Studies on effect of various culture media on growth, sporulation and morphological variations of Alternaria alternata (Fr.) Keissler. Flora and Fauna, 12(2): 247248.

Pria, M.D., Bergamin, D., Filho, A., and Amorim, L. 1997. Evaluation of different culture media for sporulation of Colletotrichum indemuthianum, Phaseosariopsis griseola and Alternria spp. Summa Phytopathol. 23: 181-183.

Priya, P., and Harika, D. 2016. A review on multiple uses of Cyamopsis tetragonoloba. (Clusterbean). Indian J. Avd. Tech. Eng. Sci., 4(1): 55-59.
Reddy, D. S., Nagare, P.K., Reddaiah, K., and Reddy, B.R. 2014. Effect of integrated nutrient management on growth, yield, yield attributing characters and quality characters in clusterbean (Cyamopsis tetragonoloba (L.) Taub.). The Ecoscan. 4: 329-332.

Sharma, S. R. 1983. Effect of fungicides on the development of Alternaria blight and yield of clusterbean. Indian $J$. Agric. Sci. 53 (11): 932-935.

Singh, P. C., Singh, R. Kumar, D., and Maurya, V. K.. 2013. Effect of different media, $\mathrm{pH}$ and temperature on the radial growth and sporulation of Alternaria alternata f. sp. lycopersici. Hort. Flora Res.Spect. 2(2): 175-177

Singh, V., Kumar, P. and Sinha, A. P. 2001. Influence of different media, $\mathrm{pH}$ and temperature on growth and sporulation of Alternaria alternata (Fr.) Keissler, causing Alternaria blight of chickpea. Legume Res., 24(4): 238-242.

Waghunde, R. R. and Patil, R. K. 2010. Physiological studies of Alternaria fruit rot (Alternaria alternata) of Aonla. J. Pl. Disease Sci., 5(1): 73-75.

\section{How to cite this article:}

Satish Sharma, Pragati Saini, Ajay Kumar, Reeti Singh and Pandya, R.K. 2018. Assessment of Different Culture Media on the Growth and Sporulation of Alternaria cucumerina var. cyamopsidis causing Alternaria blight of Clusterbean. Int.J.Curr.Microbiol.App.Sci. 7(09): 3308-3313. doi: https://doi.org/10.20546/ijcmas.2018.709.410 